\title{
Research on the Low Carbon Evolution Mechanism of the Coal Enterprises based on Genetic Algorithm and Game Analysis
}

\author{
Jia Xianmin ${ }^{1,2 *}$, Lu Caiwu ${ }^{1}$ and Wang Xilian ${ }^{3}$ \\ ${ }^{1}$ School of Management, Xi'an University of Architecture and Technology, China \\ ${ }^{2}$ Business School, Xi'an International University, China \\ ${ }^{3}$ School of Management, Xi'an University of Science and Technology, China \\ jxmmin@sina.com
}

\begin{abstract}
In this paper, we conduct research on the low carbon evolution mechanism of the coal enterprises based on genetic algorithm and game analysis. Presently, internationally the industrial security development presents colony, fusion and ecology three general trends, the low-carbon development became the global countries mutual recognition. Traditional industry cluster is a complicated network which is gradually formed by a large number of subjects in the repeated game, through constant imitation, learning and choosing the best choice, in search of the strategy of maximum survival probability. The emergence and selection of low-carbon strategy is the main body of the cluster in low-carbon evolution of the game, through continuous imitation, as learning and try to choose the best selection process. Under this basis, this paper proposes the low carbon evolution mechanism to help determine the further development trend of the enterprise. The genetic algorithm and game analysis are jointed to optimize the model.
\end{abstract}

Keywords: Low Carbon, Evolution Mechanism, Coal Enterprises, Genetic Algorithm, Game Analysis, Modelling Analysis

\section{Introduction}

Low carbon economy is referring to under the guide of the sustainable development, through technical innovation, system innovation, industrial transformation, new energy development and some other means, as far as possible to reduce the high carbon energy consumption with a form of the economic development to achieve economic and social development and ecological environmental protection win-win. The traditional extensive mining coal enterprises in resource utilization are low and serious resource waste. Coal enterprises mostly for high energy consumption, heavy pollution as technical equipment, backward production technology while the resource comprehensive utilization rate is low and at present and the causes of the coal enterprise resource comprehensive utilization are low with the following points.

- A large number of associated, Symbiotic Resources and low utilization of waste.

- Coal mining waste of resources in the process of serious. Enterprises to give up thin coal seam and the mining more difficult coal resources, there are some enterprises to adopt a full-mining approach, only mining the middle layer, to abandon the top and bottom of coal mining, there are some companies mining methods backward.

- After the washing of coal mining is relatively low. Although in the recent years, domestic coal washing processing technology has made great progress, while compared with the United States, Russia and other coal producing countries there is a large gap between the rates of washing.

${ }^{*}$ Corresponding Author 
China has more coal production enterprises the average production capacity of small, the coal industry is the highest degree of the market-oriented, one of the most competitive industries. In the recent two years, China has increased the regulation of coal production, through the customs, stop, and turn, to a certain extent, the production of small coal mines poor condition of the phenomenon has been improved, but this is a long process, and not a short period of time to be a fundamental solution. For coal product, it is the core of the modern technology of clean coal production technology, in today's society is not only to the requirement of coal come from the underground coal mining to the social needs, the number of requirements and provide to improve efficiency that is beneficial to reducing emissions of coal or any processed products thereof.

To achieve the requirements of the basic way is to change the production process of coal enterprises, namely the raw coal mining to the user use route as change for raw coal mining to processing quality or conversion to final users using a new technique route. In the following figure one, we demonstrate the related features.

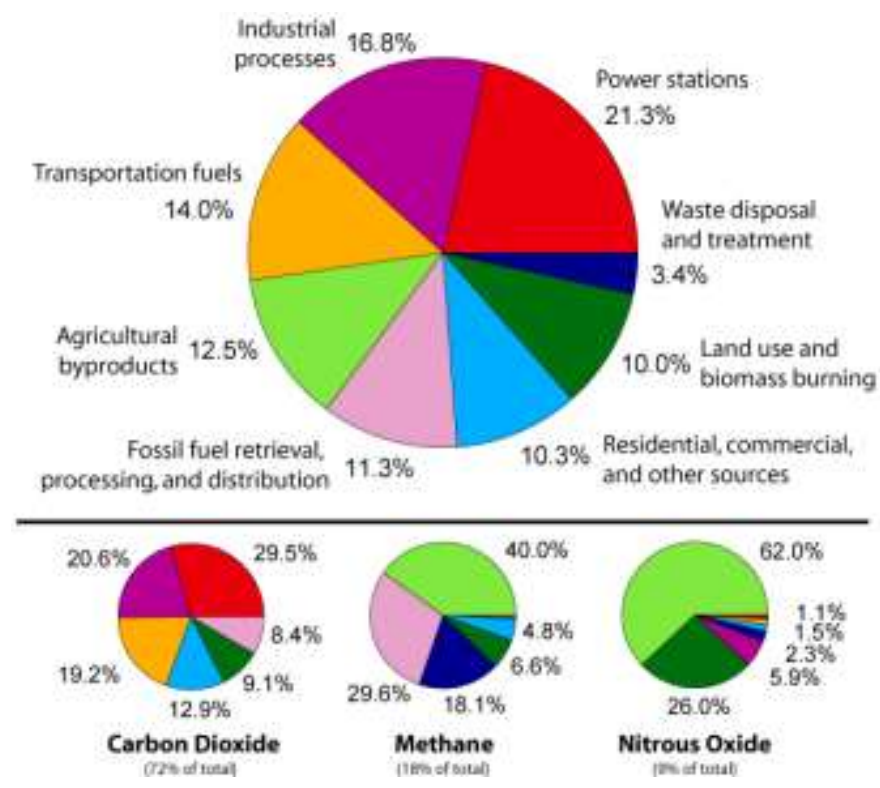

Figure 1. The Current Condition of the Carbon Evolution Mechanism

In this research paper, to deal with the mentioned challenges, we conduct analysis on the low carbon evolution mechanism of the coal enterprises based on genetic algorithm and game analysis. In the later sections, we will discuss in detail.

\section{The Theoretical Framework of the Proposed Methodology}

\subsection{The Revised Genetic Algorithm}

The genetic algorithm, proposed in 1975 by the Professor Holland that is the random optimization algorithm of a natural selection and heredity mechanism of simulation nature species community, simulates in the project with the evolutionary process of chromosome survival of the fittest the solution process of issue. The genetic algorithm is the simulation nature organic evolution process and kind of basic self-organization and auto-adapted of the artificial intelligence technology mechanism solution minimum problem, and its basic philosophy is one algorithm of the process search optimal solution the simulation nature heredity mechanism and organic evolution discussed to form that had the solid biological foundation; It provides from the simulation of intelligent generation process viewpoint to biomass energy which has the bright cognition study significance; It suits not having the 
expression or has any class function of expression and has achievable parallel computing behavior; It can solve any type actual problem that has the widespread application value.

Although genetic algorithm has been widely used in the many optimization problems, compared with the application of genetic algorithm theory itself, it has a lot of space. At present, genetic algorithm entered the great development time, the fundamental research or the applied research is very active domains. Especially basic research of the genetic algorithm in the general application is to appear especially noticeably. Not only expands in the applied field unceasingly, but also is carrying on the ability in optimized and rule learning considerably is also enhanced. A simple genetic algorithm consists of four parts: coding mechanism, fitness function, genetic operator, control parameter, etc. Simple genetic algorithm is basic encoded by 0 and 1 , and 0 and 1 are called genes, which are composed of binary strings and that binary strings. The chromosomes and chromosomes correspond to the solution of the optimization problem, and the transformation of gene space and solution space is realized by coding and decoding process and the evaluation criterion of the survival of the fittest in the genetic algorithm is expressed by the fitness function through the fitness function that we can determine the quality of the solution, to determine the merits of chromosomes. In the Figure two, we show the procedure.

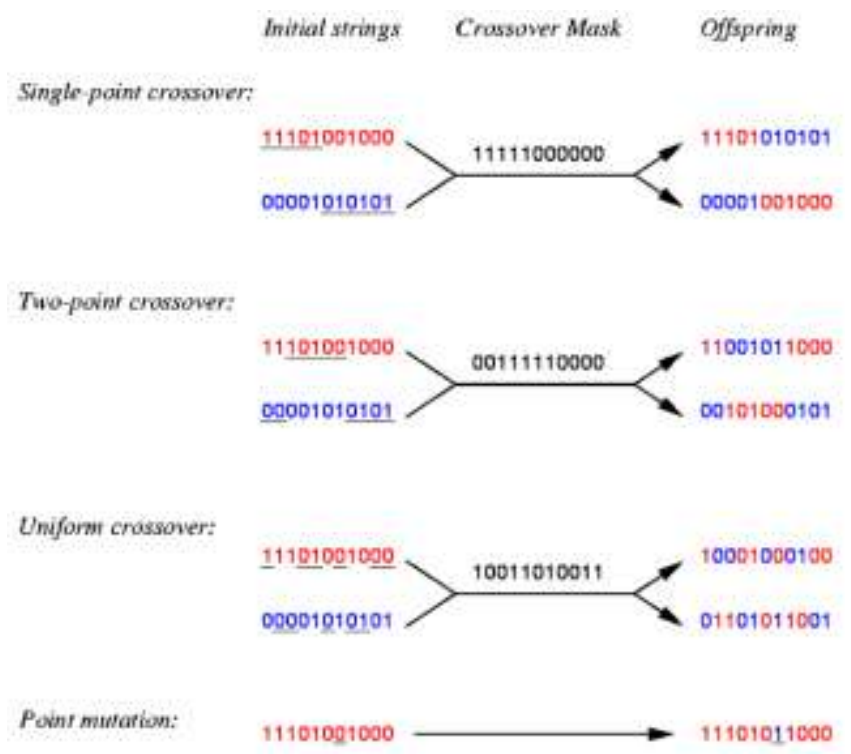

\section{Figure 2. The Inner Procedures of the GA Algorithm}

Sums up to see that at present people's improvement to the genetic algorithm mainly focuses in the following several aspects: The code expressed that the fitness functions and the choice strategy, the controlled variable, the genetic operator, population and algorithm fusion which can be organized as the following aspects.

* Control parameters. The choice of controlled variable in the design of the genetic algorithm is a very subtle link. The simple genetic algorithm uses the parameter experiential design method, while the designer often must give dual attention to measure various factors, and therefore it has very big blindness.

* Genetic operator. Crossover operator has the effect of a wide range of the search, mutation operator, have the effect of local search and jump out of local minima. For how to balance the coordination of the relationship between them, both at the home and abroad scholars invest a lot of energy in study of genetic operators and according to the actual problem to create all kinds of new operator.

* Hybrid algorithm. Because the genetic algorithm has wide applicability as easy to mutual penetration with other intelligent optimization algorithm and that mutual 
complement each other between the algorithms of hybrid algorithm can gain an unexpected effect.

For the systematic optimization of the algorithm, we should consider the listed aspects. The real coding mechanism is adopted, which directly encodes the solution space of the optimization problem, which not only eliminates the encoding and the decoding process between the gene space and the core solution space, but also improves the accuracy of the solution and reduces the calculation amount of the optimization process. The related basic transformation and analysis can be reached as the listed formulas.

$\alpha^{*}=\alpha+(\beta-\alpha) \times w$

$\beta^{*}=\beta+(\beta-\alpha) \times(1-w)$

Where the parameters of the $(\alpha, \beta)$ represents the chromosome, the $\mathrm{NC}$ spin forming of genetic algorithm generally includes the community scale, the convergence criteria, the hybrid probability and mutation probability. The NC spin forming relates to the genetic algorithm the precision, reliability and computing time and other factors, and affects the result quality and system performance. Therefore, the research of NC spin forming in the genetic algorithm is important. Genetic algorithm as an optimization algorithm, although its robustness is good, but sometimes encountered multi-peak function, and sometimes inevitably converges to the local optimal value, rather than the global optimal value of the existence of these two reasons while often in the selection process, a loss of the valuable chromosomal information occurs. Under this condition, the basic parameters can be then updated as the following formula $3 \sim 4$.

$\alpha^{*} \mid=\alpha \times(1-w \times(1-$ gen $/$ max gen $) \times 2)$

$\beta^{*} \mid=\beta \times(1-w \times(1-$ gen $/ \max$ gen $) \times 2)$

With this essential updating, the GA can be equipped with the listed features. (1) The genetic algorithm uses probability search information, the application is more flexible and the operation is simple and reliable. (2) Genetic algorithm with the code of the decision variable as operating object that is concisely direct. (3) The genetic algorithm does not require derivatives or other auxiliary knowledge, and that only affect the direction of the search function and the fitness function, the amount of information required to solve the problem of the less. (4) Genetic algorithm directly to the objective function value as the search information has the wide applicability.

Besides the parameter optimization, we also adopt the structure optimization. Improved genetic algorithm as a kind of that uncertain quasi natural algorithm, the optimization for the complex system provides a new way, and through the practice has proved effective. Although the improved genetic algorithm has extensive application value in many areas, while it still has some problems. In the following formula, we express the feature.

$V_{\text {updated }}=V_{\text {original }}+\eta\left(X_{\text {best }}-X_{\text {original }}\right)$

The PSO algorithm has and genetic algorithm certain similar characteristics, therefore Jim Kennedy also call a kind of EA. The most major characteristics of this algorithm had demonstrated to the function optimization high efficiency, according to the understanding of this article author was because it has profited from some ideas of gradient optimization. The universality of GA application determines its importance, and its wide range of the improvement space also illustrates the feasibility of the research on its basic improvement strategy. In the face of the rapid update, context plays a genetic algorithm, throughout the 
theory of genetic algorithm research situation of development and improvement measures, we found that the high parallelism of genetic algorithm, wide adaptation and strong robust characteristics that make it special for traditional search algorithm to solve complex areas.

\subsection{Game Analysis Principles and Theoretical Features}

Mine green production and green mining technology from the angle of the generalized resources to recognize and treat the coal, gas, water, etc. all can take advantage of various resources, the starting point is to prevent or reduce the exploitation of the coal and other resources to the environment as much as possible negative effects, the goal is to get the best economic benefits and social benefits, we respectively from the potter five model five aspects to analyze current situation of the development of industry as follows.

* Supplier bargaining power. Because the country speeds up regarding adjustment of the energy sources structure step, the non-fossil energy source proportion will increase, the demand of coal transport will be greatly affected.

* Existing competition among the enterprises. Because of the depressed coal market price war continually, the external situation is just a price war, industry internal defects is the root cause.

* Potential entrant threat. The coal industry, and the industry there is a strong economies of scale, strict national administrative access control.

* Substitute threat. The international energy production and expense are developing in clean, the low-carbon direction, to deal with the energy development trend, our country vigorously develops the new energy and renewable energy, the coal is facing the huge substituted threat.

* The buyer's bargaining power. Coal product homogeneity serious, China's main coal procurement users of metallurgy and building materials market concentration is improving and constantly getting advantages.

Assuming that the coal enterprises and the government are rational economic man, based on this assumption, we establish a static game model between enterprises and the government. Coal enterprises in the production, we can choose to use the green mining technology or green mining technology, the government may choose to supervise or not to regulate the two strategies. Also supposed before coal enterprise and government make the decision-making, does not know that the motion of opposite party, can think their motions simultaneously are conducted, and this countermeasure belongs to the complete information static game, then game model between coal enterprise and government as shown in the Table 1.

Table 1. Game Model between Coal Enterprises and Government

\begin{tabular}{|c|c|c|}
\hline $\begin{array}{c}\text { Government } \\
\text { strategy }\end{array}$ & $\begin{array}{c}\text { With green mining } \\
\text { technology }\end{array}$ & $\begin{array}{c}\text { Without green mining } \\
\text { technology }\end{array}$ \\
\hline Supervise & $-\varphi-C, \Phi_{1}+\varphi$ & $\psi-C-H, \Phi_{2}-\psi$ \\
\hline Non-supervise & $-\varphi, \Phi_{1}+\varphi$ & $-H, \Phi_{2}$ \\
\hline
\end{tabular}

If the coal enterprises to choose the green mining technology, and the government had better choose not regulation but corresponding to this is when the government chose not to regulation, and coal enterprises to adopt green mining technology for optimal, to this, the government should choose regulation, so coal enterprises have to adopt green mining technology. So, the two sides interests always cannot reach agreement any pure strategy combinations have a participant can be separate to change its strategy, in order to obtain greater benefits. As a result, the game there is no automatic balance strategy combination 
which belongs to the mixed strategy problem in complete information. In the Figure 2, we show the game analysis framework.

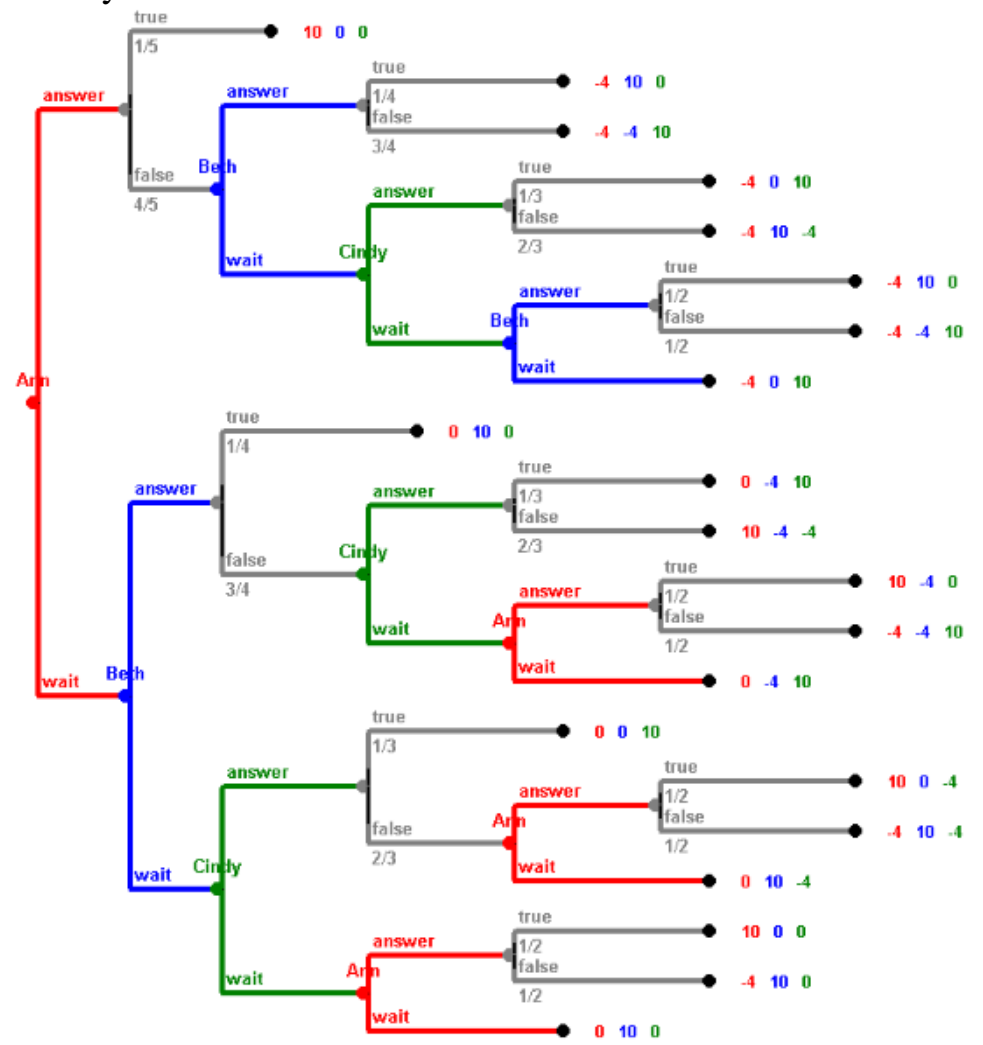

Figure 3. The Game Analysis Steps Demonstration and Verification

We will now model dynamic. Assume that the government checks every coal company only once, and that the government knows all the information that is checked before it is checked. This kind of strategy can be regarded as a kind of complete information dynamic game. In the numerous repeated game as we can see: due to the short-term interests of the drive, coal companies choose not to use green mining technology for production, and the government once aware of coal mining enterprises do not use green mining technology to pollute the environment and hold the enterprises to check. Under this condition, we can shift the proposed methodology based on the listed features.

Under the condition that the $\Phi_{1}<\Phi_{2}-\varphi-\psi$, the coal enterprise is using the income of green mining technology is smaller than does not use the income of the green technology mining.

Under the condition that the $\Phi_{1}>\Phi_{2}-\varphi-\psi$, the coal enterprises in the use of green mining technology with green mining income is greater than the income, and the coal enterprises in order to obtain long-term maximum profit will stick with the green mining technology, government regulation, government and enterprises have their own best interests, to achieve a "win-win" situation. The game can be carried out indefinitely. In the optimal strategy of the analysis government, supposed that the government only cares about own payment, only when he knew the coal enterprise has not used the green mining technology to supervise. And if before coal enterprise, that has not used the green mining technology, causes the pollution to the environment, the government will expect that the later coal enterprise will not have used the green mining technology to produce and then its optimal strategy supervises. The revised interest can be formulized as the follows.

$\Delta$ Interest $=\frac{\Theta_{1}+\varphi}{\lambda_{e}}$ 


\section{The Principles of the Low-Carbon Evolution}

The energy intensive industry chain refers to the basic energy dependence strong industry chain. It based on the industrial internal division of administrative duties and supply-demand relationship by carries on the mining, processing and use related energy extensive enterprise to some natural resources, according to the production process, through the network organization that the information and other knowledge of the exchanges and sharing form. Energy-intensive industrial chain as a traditional industrial chain, the degree of inter-industry and the relate depth of the processing of resources determines the level of the low-carbon industry chain. The stronger the industrial linkage, the closer the chain, the higher the efficiency of energy use, the smaller the intensity of carbon emissions and the longer industry chain, indicating that the deeper the processing of resources, the higher the added value of industrial chain, the use of the energy per unit of output the lower the amount, the smaller the carbon emission intensity.

Different from the traditional technology innovation in the order to obtain the core goal of the commercial profit, low carbon technology innovation incorporates energy saving, green, low carbon and other elements, which is the public interest of the social mass production and life as well. The characteristics of the low carbon technology innovation mainly include the following aspects.

- Low carbon technology innovation, its essence is the high energy efficiency and clean energy structure, the core of which is based on the energy-saving emission reduction technology innovation and some new energy technology innovation, thus breaking the whole society is facing energy bottlenecks and ecological environment, which involves The interests of the whole society of energy consumption and interests of working and environment security.

- The low carbon economy is after the Industrial Revolution and information revolution a brand-new industrial revolution. The low carbon economy realizes through low-carbon innovation, the low-carbon innovation that has expedited the development of related low-carbon industry.

- The existing industrial structure of our country needs a period of the time to adjust to be reasonable, this is a long process. In addition, China is now in the rapid development of new industrialization and urbanization stage, with upgrading of consumption structure and a large number of city infrastructure construction will still rely on traditional industries for a long period of time.

- Region low-carbon innovation is a long-term systems engineering, needs and other interactions of essential factors to realize with the general aid of the technology, knowledge, system, culture, service, the low-carbon innovation needs the knowledge foundation, the systemic guarantee and the culture to eagerly anticipate and service promotion.

Under this background, we then propose the carbon emission locking to help the further analysis of the low-carbon evolution. In fact, the concept of "carbon lock" is the specific application and extension of path dependence and lock-in concept in technology and institutional change economics to explain the change of low-carbon technology system. Scholars believe that the current industrial economy locked in a fossil fuel based the carbon intensive energy systems, and a sustained market failure and policy failure, and thus hindered the spread of low carbon technology. This paper argues that the development path of the technical system should be understood as an evolutionary process based on path dependence and path creation, with both emergent and the constructive non-stop. The evolution of the path of the technical system is divided into the three stages: 1 , path generation stage. Path generation and 
path creation can be divided into two paths: path development and stability. The system of technology at different levels (technology, enterprises and institutions) increasing returns, learning effects and network externality and a series of positive feedback mechanism will make the final formation of the technical system path and tend to stability; 3 , path differentiation stage.

Although technical system way tends to under the function of the regeneration mechanism gradually stably, while the development of general way will still display emergence and construction characteristics at this time while at this stage, even if no promotion of mover, the regeneration circulation will also solidify the development of way. The data shown in the figure 4 proves our proposal.

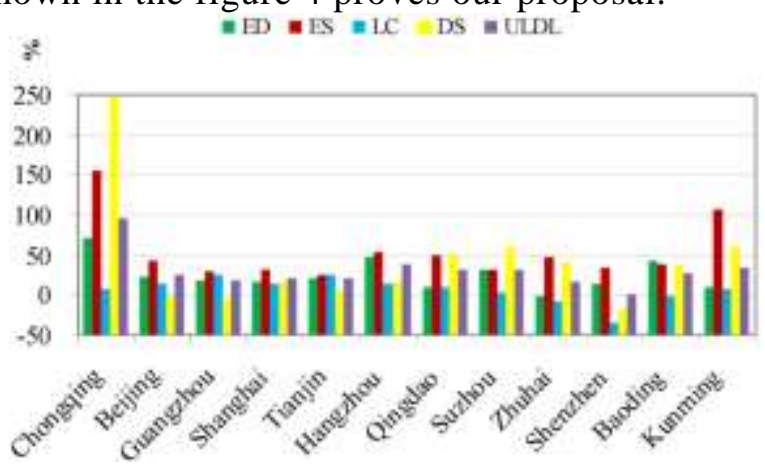

Figure 4. The Supportive Data for the Low-Carbon Evolution

\section{Low Carbon Evolution Mechanism of the Coal Enterprises Finalized Analysis and Systematic Modelling}

\subsection{Coal Enterprise Modeling Analysis}

Promotes the CSM is coal enterprise obtains the safeguard of survival and development in the intense market competition, according to the construction science reasonable highly effective coal enterprise supply chain, needs to the information flow, logistics and as fund flow to carry on the active control in the supply chains, organically combines to form the supplier, the stock management, the manufacturing, the basic logistics transportation, the distributor and customer a body, facilitates the coal enterprise internal resource with the optimal allocation of external resource, to obtain more highly effective running process. According to the coal enterprise CSM model, when carries on the supply chain simulation modeling of coal enterprise using the computer, joins in which the logistics transportation specially, to improve the coal enterprise supply chain.

How to optimize the scale of the coal enterprises, there is a problem here. The theory method to determine the economic scale of accounting method and engineering method, the survival of the fittest method etc. because the benefit from scale economy is not easy to be perceived by people, it is not easy to be perceived by the people, so the method is limited in practical application. Application of the basic theory and methods of analysis, optimization of production scale can be divided into the epitaxial production scale of the overall optimization and content-type production elements of the optimal combination of two levels. In different production systems, the proportion of the two levels is determined by the technical conditions of the system.

Under this basis, the core optimization function for the whole system can be organized as the follows.

$\min \theta=V_{D} \quad$ s.t. $\quad \sum_{j=1}^{n} X_{j} \lambda_{j}+\bar{S}=\theta X_{0}$

When the reality builds and application production function model, how to comment the validity of activity to be important as regarding the coal enterprise, affects its scale of 
production the factor to be many, there are able the statistical index of quantification, there are other factors of very difficult quantification, such as that geological condition change, market and the policy factor. When determining the weights of these influencing factors, easily by the influence of policy-maker subjective factor. How to solve the model parameters is a very important step. The traditional regression analysis method to calculate parameters of the production function, due to the effect of collinearity among independent variables often makes the result a serious distortion, making the production function of practical value has been greatly affected, it is difficult to build the largest production function model in the process of. We suggest that the principal component method is used to eliminate the co linearity between the independent variables, namely, by transforming the original variables into several orthogonal factors. Therefore, we take the formula 8 as the reference.

$$
X_{\text {optimal }}=\left(X_{i k}-\bar{X}_{k}\right) / S_{k}
$$

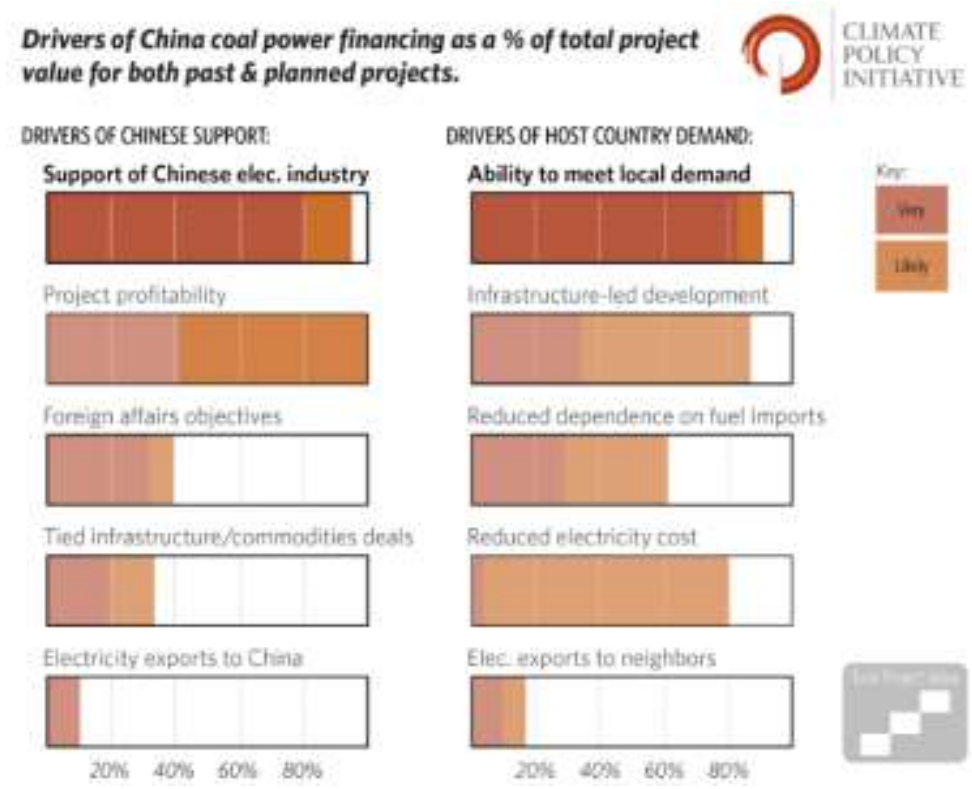

Figure 5. The Coal Enterprise Modeling Analysis and Key Parameters

\subsection{Suggestions for the Coal Enterprise Development}

Based on the prior discussions and analysis, we determine that the essential issue for dealing with the coal enterprise development is the management. First of all, we should take the listed suggestions into consideration.

Introduction activity-based costing and other advanced cost ideas along with constant development of time, coal enterprise's operation and management must with the international standard that is not only makes coal enterprise be able momentarily to pay attention to the trend of international coal market, can implement international most advanced coal management immediately, carries on the effective management and monitoring to the cost management that the coal business comes.

Each coal enterprise must act according to own development situation, the production characteristics and management style, that considers the limiting factor in each aspect comprehensively, thus establishes including the production cost management, security cost management and transportation cost management all-around cost management systems. 
In the cost management, enterprise managers should launch all managers, financial personnel, accounting personnel, technicians and general front-line production staff is actively engaged in the cost management of enterprises, mutual inspection, mutual supervision, and constantly improve their business quality, minimize work errors and loopholes to reduce production costs in the work of unnecessary expenditure and waste of funds.

Besides the mentioned items, the inventory management is also essential for the coal enterprises. In the specific operation, the inventory management methods can be divided into traditional inventory management methods and the modern inventory management methods. For the systematic suggestion, we recommend the ABC methodology. In general, using ABC classification management, the coal enterprise warehouse management personnel can not only find out the tube material storage conditions, especially A kind of material use and consumption, improve the quality of the materials planning and planning accuracy, the initiative and to use good money, but also change the warehouse management personnel in the past "just for work, just, whatever money" one-sided approach, make coal enterprise material management from custody gradually turned to enterprising, which took to the track of scientific management, in ensuring continuous, stable and safe production of coal enterprises at the same time, conservation management. For the further suggestions, we also recommend the listed methodologies.

$>$ Corporate plan forecast and supplies strategy. CPFR is not only a concept, but also a series of activities and processes. The technology from the overall point of view, the development of a unified management objectives and the implementation of the program approach to inventory management as core.

$>$ Joint inventory management. JMI can partially eliminate the supply chain fluctuations caused by supply chain uncertainties and demand information distortions, and improve the supply chain synchronization.

\section{Conclusions}

In this literature analysis, we conduct research on the low carbon evolution mechanism of the coal enterprises based on genetic algorithm and game analysis. Our country is at the rapid economic growth and crucial phase of industry restructure, the development low carbon economy not only can realize the low-carbon emission or widespread development of the zero carbon emission, the energy high efficiently utilizing and clean energy, thus realizes energy conservation and the emission reduction, to construct the goals of two societies that is the transformation economic development way that takes the new-style industrialization road to promote the modernized regulation the major force. In the paper, we integrate the theories of the genetic algorithm and game analysis to propose the new paradigm for the related issues that will help promote the construction of the related industries and essentials.

\section{Acknowledgments}

The work of this paper is supported by the National Natural Science Youth Program (71303184); Ministry of Education Humanities and Social Sciences Youth Project (12YJC790075); Shaanxi Province Soft Science Project (2013KRM05). 


\section{References}

[1] Z. Hongbo, "Genetic algorithm and evolutionary support vector machine", Journal of Shaoxing University, vol. 24, (2004), pp. 25-28

[2] E. P. Silva, W. Xu, C. Föjer, V. Bliznuk, Y. Houbaert, J. Sietsma and R. Petrov, "Microstructural Evolution of a Low-Carbon Steel during the Austenite Decomposition Below Ms", (2014).

[3] M. A. Jano-Ito and D. Crawford-Brown, "Socio-technical analysis of the electricity sector of Mexico: Its historical evolution and implications for a transition towards low-carbon development", Renewable and Sustainable Energy Reviews, vol. 55, (2016), pp. 567-590.

[4] J. Qiao, Y. Liu, F. Hong and J. Zhang, "A review of catalysts for the electroreduction of carbon dioxide to produce low-carbon fuels", Chemical Society Reviews, vol. 43, no. 2, (2014), pp. 631-675.

[5] L. U. Ri-Huan, L. I. U. Xiang-Hua, Y. A. N. Shu and L. I. U. Li-Zhong, "Mechanism of Microstructure Evolution in Low Carbon Steels by Flash Processing", Journal of Northeastern University (Natural Science), vol. 11, no. 011, (2015).

[6] M. Shalom, S. Gimenez, F. Schipper, I., Herraiz Cardona, J. Bisquert and M. Antonietti, "Controlled carbon nitride growth on surfaces for hydrogen evolution electrodes", Angewandte Chemie, vol. 126, no. 14, (2014), pp. 3728-3732.

[7] Y. F. Ivanov, D. A. Kosinov, N. A. Popova, V. E. Gromov and S. V. Konovalov, "Evolution of the structure and phase composition of low-carbon ferrite steel under conditions of hydrogen saturation and deformation", Bulletin of the Russian Academy of Sciences: Physics, vol. 78, no. 3, (2014), pp. 237-240.

[8] W. Blyth, D. W. Bunn, M. Chronopoulos and J. Munoz, "Systematic Analysis of the Evolution of Electricity and Carbon Markets under Deep Decarbonisation”, NHH Dept. of Business and Management Science Discussion Paper, (2014/39), (2014).

[9] M. H. Moradi and M. Abedini, "A combination of genetic algorithm and particle swarm optimization for optimal DG location and sizing in distribution systems", International Journal of Electrical Power \& Energy Systems, vol. 34, no. 1, (2012), pp. 66-74.

[10] C. Bi, Q. Zhang, R. Bao and H. Wang, "SAR image restoration and change detection based on game theory", In Intelligent Computing and Internet of Things (ICIT), 2014 International Conference on IEEE, (2015) January, pp. 55-58

[11] H. S. Aplak and O. Türkbey, "Fuzzy logic based game theory applications in multi-criteria decision making process", Journal of Intelligent \& Fuzzy Systems, vol. 25, no. 2, (2013), pp. 359-371.

[12] P. H. Nguyen, W. L. Kling and P. F. Ribeiro, "A game theory strategy to integrate distributed agentbased functions in smart grids", IEEE Transactions on Smart Grid, vol. 4, no. 1, (2013), pp. 568-576.

[13] N. Azam and J. Yao, "Analyzing uncertainties of probabilistic rough set regions with game-theoretic rough sets”, International Journal of Approximate Reasoning, vol. 55, no. 1, (2014), pp. 142-155.

[14] A. Arabali, M. Ghofrani, M. Etezadi-Amoli, M. S. Fadali and Y. Baghzouz, "Genetic-algorithm-based optimization approach for energy management", IEEE Transactions on Power Delivery, vol. 28, no. 1, (2013), pp. 162-170.

[15] S. Oreski, D. Oreski and G. Oreski, "Hybrid system with genetic algorithm and artificial neural networks and its application to retail credit risk assessment", Expert systems with applications, vol. 39, no. 16, (2012), pp. 12605-12617.

[16] M. H. Ahmadi, M. A. Ahmadi, R. Bayat, M. Ashouri and M. Feidt, "Thermo-economic optimization of Stirling heat pump by using non-dominated sorting genetic algorithm", Energy Conversion and Management, vol. 91, (2015), pp. 315-322.

[17] A., Lachapelle, J. M. Lasry, C. A. Lehalle and P. L. Lions, "Efficiency of the price formation process in presence of high frequency participants: a mean field game analysis", Mathematics and Financial Economics, vol. 10, no. 3, (2016), pp. 223-262.

[18] J. Cámara, G. A. Moreno and D. Garlan, "Stochastic game analysis and latency awareness for proactive self-adaptation", In Proceedings of the 9th International Symposium on Software Engineering for Adaptive and Self-Managing Systems, ACM, (2014) June, pp. 155-164.

[19] S. Arnab, T. Lim, M. B. Carvalho, F. Bellotti, S. Freitas, S. Louchart and A. De Gloria, "Mapping learning and game mechanics for serious games analysis", British Journal of Educational Technology, vol. 46, no. 2, (2015), pp. 391-411.

[20] X. Hu, Z. Liao, J. Wang and J. He, "Shared Parking Policy Analysis Based on Game Theory", In 15th COTA International Conference of Transportation Professionals, (2015) July. 
International Journal of u- and e- Service, Science and Technology

Vol. 10, No. 1 (2017) 